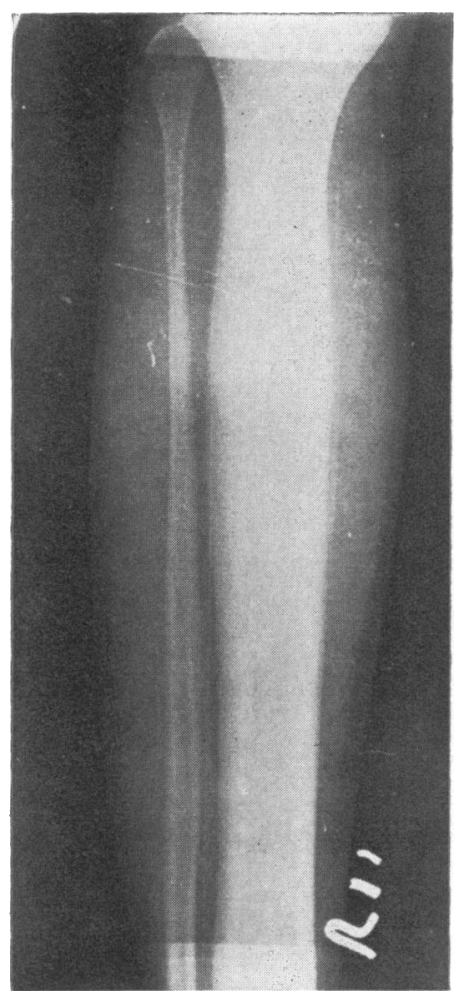

FIG. 3.- Aged 17 years. X-ray of the right leg showing tibial cortical hyperostosis.

Van Buskirk, F. W., Tampas, J. P., and Peterson, O. S., Jr. (1961). Infantile cortical hyperostosis. American fournal of Roentgenology, Radium Therapy, and Nuclear Medicine, 85, 613.

S. TAJ-ELDIN ${ }^{\star}$ and JASIM AL-JAWAD

Department of Paediatrics, University of Baghdad, and Children's Welfare Hospital, Baghdad, Iran.

$\star$ Deceased.

\section{Raised Serum IgM Levels in Neonatal Endemic Diarrhoea}

For over 2 years cases of diarrhoea occurred intermittently on the Special Care Nursery of the Bolton District General Hospital, and no cause was found on routine investigation. During the period of this study, from December 1968 to April 1969, 209 babies were admitted into the unit and 44 of these developed diarrhoea, but only 25 of these were selected for special study because the other 19 cases had idiopathic respiratory distress syndrome (6), asphyxia neonatorum (1), haemolytic disease of the newborn (3), hypoglycaemia (6), intracranial haemorrhage (2) or urinary infection (1) as well as the diarrhoea.

Of the 209 admissions, 102 were of low birthweight $(2 \cdot 5 \mathrm{~kg}$ or less) and 68 were small-for-dates. Of the 44 cases with diarrhoea, 35 were of low birthweight, and 24 were small-for-dates. Of the 25 cases under study, 18 were of low birthweight and 15 were small-for-dates. The incidence of diarrhoea was significantly higher in small-fordates infants $\left(\chi^{2}=11 \cdot 27\right.$ with 1 D.F., $0 \cdot 001>P>$ $0.005)$. Male infants showed a striking preponderance over female in susceptibility to the illness $\left(x^{2}=4 \cdot 18\right.$ with 1 D.F., $\left.0 \cdot 05>P>0 \cdot 025\right)$.

The clinical features were fairly similar in all cases. The affected infants had either lost weight or failed to gain weight shortly before the onset of diarrhoea. Lethargy and anorexia were common preceding symptoms. The stools were frequent, explosive, and watery.

The affected babies were isolated locally and barrier nursed. The milk was discontinued for 24 hours and was replaced by clear fluids (glucose and electrolytes mixture) given orally. Adequate fluid intake was ensured by tube feeding when necessary. Intravenous fluid was given in one patient who was moderately severely dehydrated. Milk feeding was reintroduced after 24 hours in gradually increasing concentration. 19 patients responded to this regimen, but in 6 oral neomycin sulphate was given because the response to clear fluids was delayed. There was no mortality.

The diarrhoea occurred in small outbreaks and relatively more cases tended to occur when the nursery was fully occupied. The symptoms developed between the 5th and 11th day of life with a peak incidence between the 8th and 10th day. The birthweight did not appear to affect the age of onset of diarrhoea. The pattern of feeding and the calorie intake of the affected cases was not significantly different from that of the unaffected babies. Only 3 babies were fed completely on human milk and none of them developed diarrhoea.

For a standard of comparison the investigations which were done on the affected cases were also carried out on a large number of unaffected babies of similar birthweight and age on the unit over the same period.

In 9 of the 25 cases the faecal $p \mathrm{H}$ was acid ( $p \mathrm{H}$ between 5.5 and 6$)$ but it quickly rose to 7 or above after 1 to 2 days of treatment. In about 12 per cent of the unaffected babies the faecal $p H$ was also acid ( $p \mathrm{H}$ between 6 and $6 \cdot 5)$.

Two viral cultures of stools were done on each case with negative results. Three specimens of 


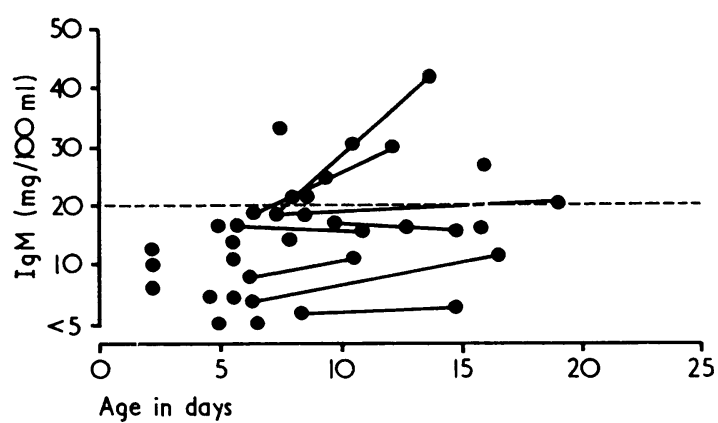

FIG. 1.-Serum IgM in the unaffected babies on the unit on different days of life during the period of observation.

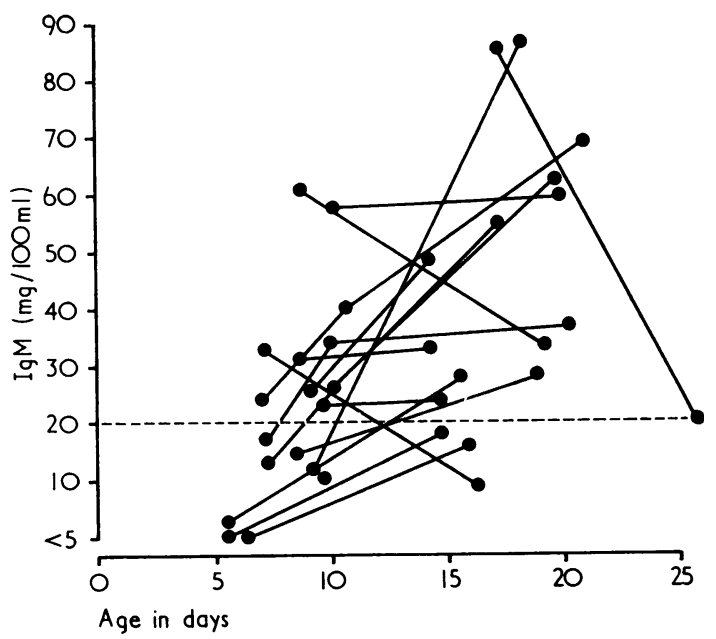

FIG. 2.-Serum IgM in the affected cases on the day of onset of diarrhoea and 5 to 10 days later.

stools were collected for bacteriological investigation. Each specimen was cultured on blood agar, McConkey, and Ludlam's media. For identification of enteropathogenic Esch. coli 10 to 12 colonies were screened by treating with $0.5 \%$ acriflavine in normal saline and if positive were further tested against the 10 common antisera. No pathogenic organisms were grown from any case.

The absolute polymorphonuclear leucocytic count on the peripheral blood of the affected cases was not significantly different from that of the unaffected babies.

Serum IgM estimations were done on the venous blood samples by radial diffusion technique (Mancini, Carbonara, and Heremans, 1965) using the antiserum supplied by Hyland Laboratories, Los Angeles, California. On the same blood samples haemoglobin, haematocrit, and plasma protein estimations were also carried out. Serum IgM in the unaffected babies is summarized in Fig. 1. The birthweight did not appear to affect the IgM levels significantly in the first few days of life. In the majority the $\operatorname{IgM}$ was below 20 $\mathrm{mg} / 100 \mathrm{ml}$ serum, and in 7 of the 9 babies it did not rise above $20 \mathrm{mg}$ when it was repeated after 5 to 10 days.

Serum $\operatorname{IgM}$ in the affected cases is summarized in Fig. 2. It was not done in 3 of the cases, and the results of 5 cases (all with IgM greater than $20 \mathrm{mg} / 100 \mathrm{ml}$ ) have not been included because the plasma protein and haematocrit values suggested some degree of haemoconcentration. It will be noticed that the IgM levels in the affected cases were not only higher than $20 \mathrm{mg} / 100 \mathrm{ml}$ but their rate of rise was also rapid.

\section{Discussion}

The behaviour of serum IgM in the affected cases was significantly different from that of the unaffected infants. It is evident that there was some different antigenic 'stimulus' for the synthesis of $\operatorname{IgM}$ in the affected cases. Connor and Barret-Connor (1967), Holzel (1970), and others have stressed the difficulty of diagnosing specific Esch. coli infection, and in about $80 \%$ of cases of infantile diarrhoea no cause is found. Our speculation is that there was an infective cause for the diarrhoea in these cases, possibly an unidentified strain of Esch. coli, but we were not able to establish this.

\section{Summary}

Endemic diarrhoea occurred in 44 babies out of 209 admitted to a special care nursery in a 4-month period. Small-for-dates babies and male babies were more susceptible to this condition. No viruses or pathogenic bacteria were isolated from the faeces, but serum IgM levels were found to be significantly raised in the babies with diarrhoea.

I thank Dr. W. Dickson and Professor J. A. Davis for encouragement and advice; Dr. D. M. Jones, Withington Hospital, Manchester, for serum IgM estimation; Dr. J. Tobin, Public Health Laboratory, Manchester, for viral cultures; Mr. A. C. C. Gibbs, Department of Social and Preventive Medicine, University of Manchester, for help with statistics; and Sister Stafford, Sister Grimshaw, and Sister Hibbert.

\section{S. A. HAIDER \\ Moorgate General Hospital, Rotherham.}

REFERENCES

Connor, J. D., and Barret-Connor, E. (1967). Infectious diarrheas. Pediatric Clinics of North America, 14, 197. 
Holzel, A. (1970). The prevention and treatment of gastroenteritis in infancy. Practitioner, 204, 46.

Mancini, G., Carbonara, A. O., and Heremans, J. F. (1965). Immunochemical quantitation of antigens by single radial immunodiffusion. Immunochemistry, 2, 235.

\section{Formalin Disinfectant Unit for Incubators}

Most infants admitted to premature baby or neonatal surgical units are nursed in incubators during part of their stay in hospital. There are many advantages of nursing these infants in incubators, but there is also one great disadvantage, the danger of bacterial colonization and contamination inside the incubator. The temperature inside the incubator approaches that of the body and many of these babies are nursed in an atmosphere of high humidity; conditions are therefore very favourable for the survival and multiplication of bacteria, especially the Gram-negative species.

In order to reduce colonization with pathogenic bacteria it is therefore necessary to clean and disinfect incubators thoroughly at short intervals usually every two or three days. Many modern types of incubator are now so designed that they are relatively easy to clean, but efficient disinfection still presents a formidable problem. As in the past disinfection by formaldehyde vapour has been time consuming and ineffective, a unit that is able to disinfect incubators automatically and efficiently in a relatively short time should be of considerable value to every premature baby and neonatal surgical unit. The model 33 formalin disinfection unit manufactured by Vickers Ltd., Medical Engineering, has been designed to disinfect incubators, hyperbaric chambers, and possibly also some types of mechanical respirator.

The prototype of this machize has been used and tested in the Liverpool Regional Neonatal Surgical Unit for over a year and lately the production model

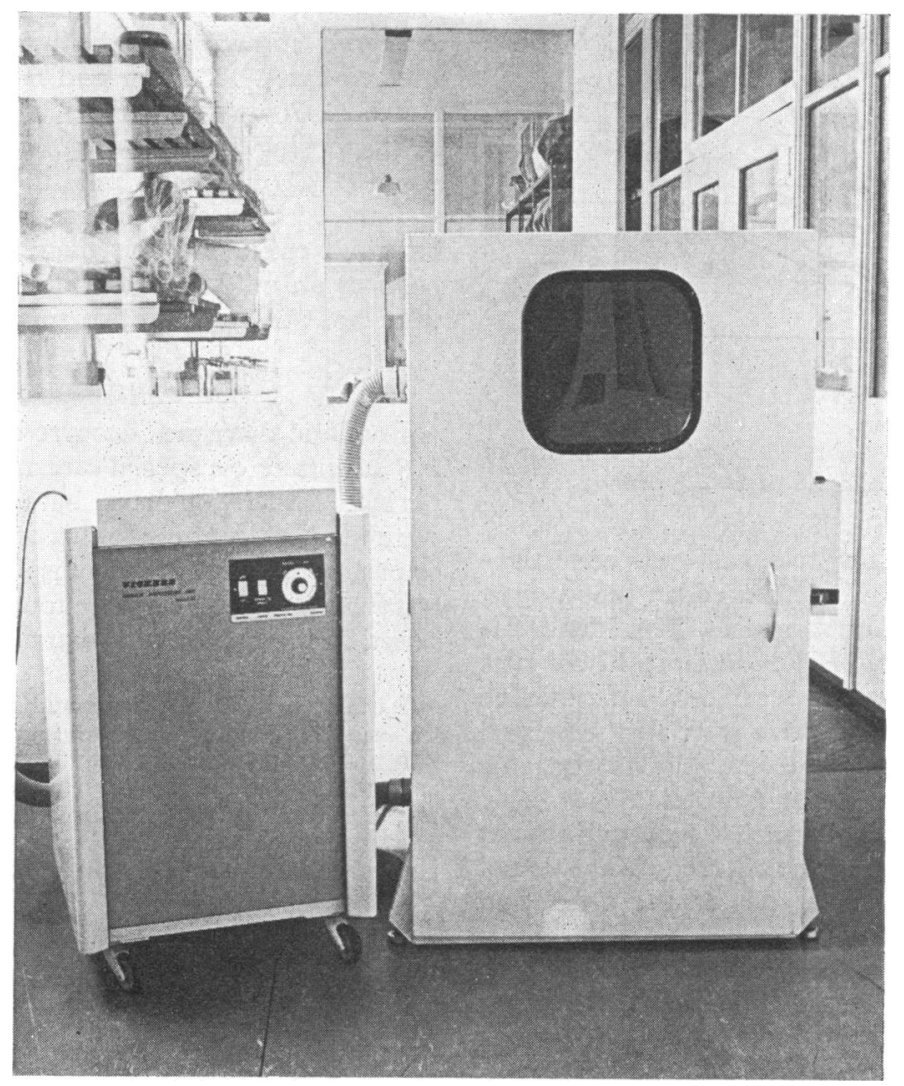

FIG. 1.-Formalin disinfection unit showing disinfection cabinet and console. 